\title{
PREDICTION OF THE POTENTIAL DISTRIBUTION OF DENDROLIMUS HOUI LAJONQUIERE IN SICHUAN OF CHINA BASED ON THE SPECIES DISTRIBUTION MODEL
}

\author{
WU, S. J. - ZHU, T. H. ${ }^{*}$ - QIAO, T. M. - LI, S. J. - SHAN, H. \\ Key Laboratory of Forest Pathology of Sichuan Province, College of Forestry, Sichuan \\ Agricultural University, Chengdu, Sichuan 611130, China \\ *Corresponding author \\ e-mail:zhuth1227@126.com \\ (Received $1^{\text {st }}$ Dec 2020; accepted $8^{\text {th }}$ Feb 2021)
}

\begin{abstract}
Dendrolimus houi Lajonquiere is one of the main leaf-eating insects of China coniferous wood and causes serious damage to the safety of the forest ecosystem. In this article, the temporal and spatial distribution patterns of Dendrolimus houi Lajonquiere in the Sichuan Province of China were analyzed by ArcGIS. Using the band set statistical method in ArcGIS, 28 environmental factors were divided, and it was found that Wind10, Prec7, Bio4, Bio15, Srad3, Prec2 and Srad5, these 7 factors played a key role in the distribution of Dendrolimus houi Lajonquiere. Combined with 7 species distribution models, including Artificial Neural Network, Bioclim, GARP, Climate Space Model, Envelope Score, Maximum Entropy and SVM, the potential distribution area of Dendrolimus houi Lajonquiere was simulated, and the simulation results were all greater than 0.8 , low, medium, and highly suitable average areas are $96227.54 \mathrm{~km}^{2}, 66062.81 \mathrm{~km}^{2}$ and $91549.23 \mathrm{~km}^{2}$ respectively, occupying $52.23 \%$ of the total area of Sichuan, China. According to the simulation results, it is necessary to strengthen the monitoring of the potential suitable areas for Dendrolimus houi Lajonquiere to prevent the large-scale damage of pine caterpillars in the forests of Sichuan.
\end{abstract}

Keywords: population dynamics, pest prediction, environmental factors, openModeller, spatial distribution

\section{Introduction}

Dendrolimus houi Lajonquiere (Lepidoptera: Lasiocampidae) is one of the most harmful leaf-eating pests of Chinese coniferous wood, parasitizing plants such as Pinus yunnanensis, Pinus densata Mast, Pinus kesiya var. langbianensis, Cryptomeria fortune (Liu, 2006; Song et al., 2019; Gou et al., 2003), which are widely distributed in Yunnan, Zhejiang, Fujian, Sichuan, Guangxi, Guangdong, Hunan, Hubei, Guizhou and other provinces (regions). India, Myanmar, Sri Lanka, Indonesia and other Southeast Asian countries also have records of infestations (Yin et al., 2002). Dendrolimus houi Lajonquiere mainly eats needles and shoots, which reduces the needles of trees and affects the normal development of plants, even leading to the death of trees, also known as "Smokeless Fire" ( $\mathrm{Li}$ and Zhong, 2013). Dendrolimus houi Lajonquiere is very tolerant, it can safely survive the winter in the form of larvae (eggs or larvae) from January to March $\left(0-5{ }^{\circ} \mathrm{C}\right)$. Old larvae mainly grow in summer (May to July). It can also be baptized with high temperature $\left(>35^{\circ} \mathrm{C}\right)$, successfully completed the development of the larvae and entered the pupal stage. The generations of Dendrolimus houi Lajonquiere vary in different regions and occur once or twice a year in Sichuan. From 2010 to 2018, the forestry area in Sichuan Province was affected by an average of more than $315 \mathrm{~km}^{2}$ each year, and the disaster area involved 51 areas. The severely affected area reached 30 square kilometers, and the occurrence rate reached 100\%. The leaves of the trees withered and fell early, which seriously affected the photosynthesis of the 
trees, and affected the growth of the trees and the natural landscape. According to onsite forestry investigations, the worm occurred in Chongzhou City and Chengdu City and the damage rate was $100 \%$ (Fig. 1). The scenic area dominated by cypress trees suffered huge economic losses and greatly restricts the development of local tourism. Dendrolimus houi Lajonquiere not only affects the safety of the forestry resources but also causes severe damage to the forest ecological environment and regional social and economic development (Xu, 2008).

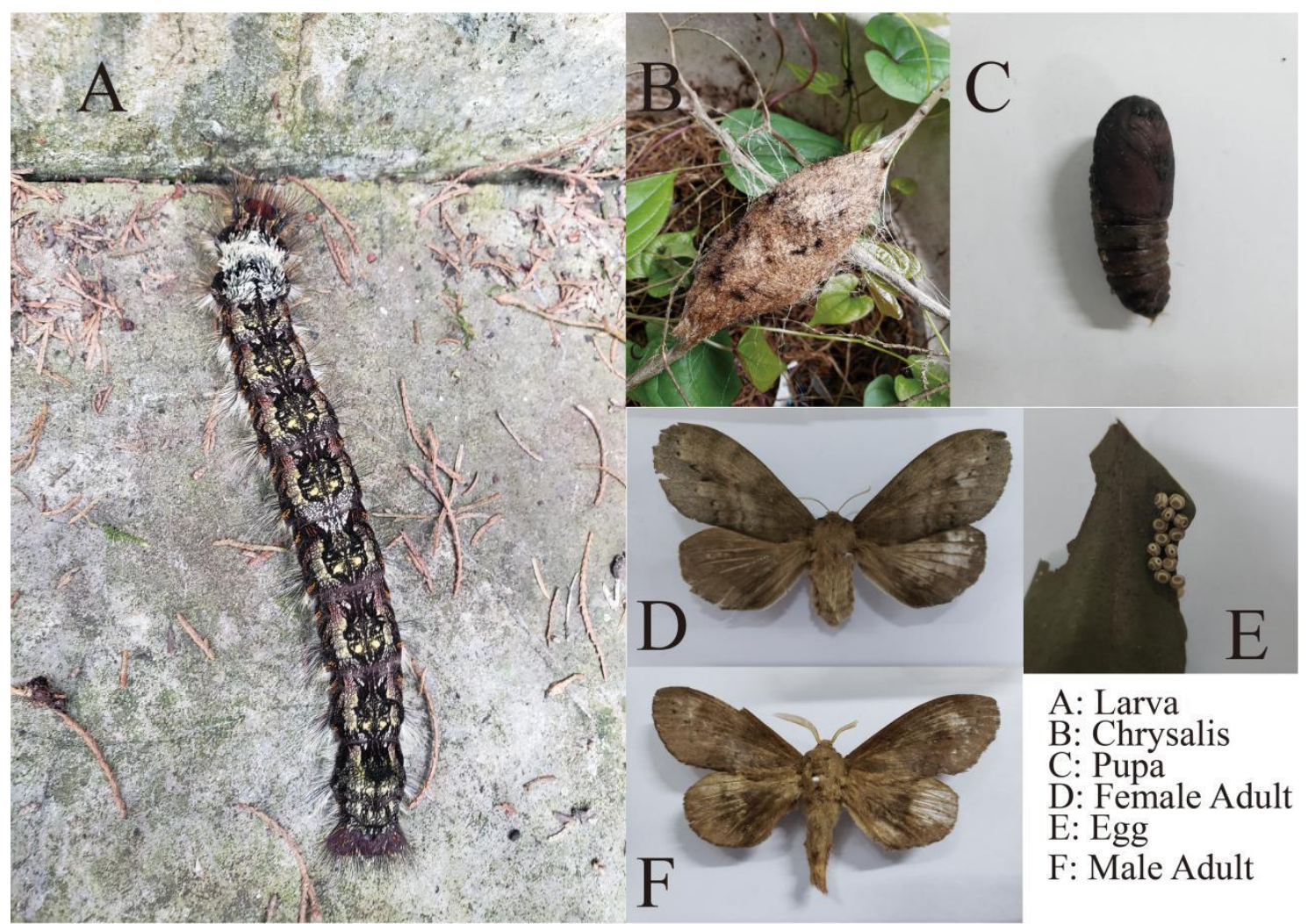

Figure 1. Five stages of Dendrolimus houi Lajonquiere; A: Larva, B: Chrysalis, C: Pupa, D: Female adult, E: Egg, F: Male adult

The insect spatial distribution pattern depends on its biological characteristics and the environment and influenced by the interaction of individuals or the distribution of the population in a geographic space, as is typical of spatial heterogeneity ( $\mathrm{Yu}$ and Liu, 2001). For studying the physiological activities of insects, interspecific competition and breeding diffusion are important and also used as the basis of monitoring and control theory. However, the completeness of the data and the small size of the study area are limitations.

The breeding diffusion of climate factors played a key role in pest distribution. First, the climate factor for pest populations had a direct impact on the ecological and physiological activities; second, the main potential distribution of parasitized plants and the forest ecosystem are also limited by environmental factors (Duan et al., 2015; Sastawa et al., 2002). The current global climate warming trend, including significant changes in temperature and precipitation, has a close relationship with the distribution of pests and their development. Thus, exploring the relationship between pests and 
climate factors can help with effective early warning, monitoring and prediction. However, this approach is still in its infancy, as most of the research involves single simple linear regression models that are roughly associated, with a lack of effective spatial visualization expression; moreover, a deep exploration of the relationship has not yet been undertaken.

A species distribution model (SDM) consists of a collection of many subjects, including ecology, higher mathematics, information science, biology, geography, statistical analysis, and quantitative ecology. Its core aims are to use the distribution data of target species and related environmental variable factors, combining different mathematical algorithms to build a model that meets the ecological needs of the species and to map the results to different times and spaces to simulate the actual distribution of species and to predict the potential distribution (Zhu et al., 2013). Currently, algorithms such as GARP (Sobek-Swant et al., 2012), MaxEnt (Phillips et al., 2006), BIOCLIM (Beaumont et al., 2005), DOMAIN (Xu et al., 2015), SVM (Drake and Guisan, 2005), GAM (Oyafuso et al., 2017), GLM (Ghareghan, 2020), BRT (Yu et al., 2020) and ENFA (Hirzel and Guisan, 2002) are widely used in the potential distribution areas of species prediction, division of suitable areas for conservation of rare species (Mukul et al., 2019), prediction of invasive alien species (Padalia et al., 2014), and determining the future impact of climate on species (Khanum et al., 2013). The current study of Dendrolimus houi Lajonquiere focuses on its biolearnability (Hua et al., 2019), sampling investigation (Zhang, 2015), forecasting (Yang et al., 2017), control measures (Zhao et al., 2003), gene sequencing (Han et al., 2019), and other factors. However, with Dendrolimus houi Lajonquiere, determining the distribution of a wide range of spatial distribution patterns involves has a high-precision model and is still in the preliminary stages.

The research objectives of this paper are mainly in three aspects: (1) Use Matlab and ArcGIS to find the temporal and spatial patterns of Dendrolimus houi Lajonquiere. (2) Determine the key environmental factors that affect the distribution of Dendrolimus houi Lajonquiere. (3) Predict the potential distribution of Dendrolimus houi Lajonquiere in Sichuan of China. Provide an important reference for the early warning and control of Dendrolimus houi Lajonquiere.

\section{Materials and methods}

\section{Study area}

Our research area is Sichuan Province $\left(26^{\circ} 03^{\prime} \mathrm{N} \sim 34^{\circ} 19^{\prime} \mathrm{N}, 9^{\circ} 21^{\prime} \mathrm{E} \sim 108^{\circ} 12^{\prime} \mathrm{E}\right)$, which is located in the southwestern region of China, covering an area of $486,000 \mathrm{~km}^{2}$ and an altitude of $188 \mathrm{~m}$ to $7556 \mathrm{~m}$. The Sichuan Basin belongs to a humid climate zone in the mid-subtropical zone with an average annual temperature of $16-18{ }^{\circ} \mathrm{C}$. The daily temperature range is small. The winter is warm and the summer is hot. At the same time, it has abundant forestry resources, of which the area of cypress is $14520 \mathrm{~km}^{2}$.

\section{Data collection and processing}

Distribution data: The Forestry Harmful Biological Information System (http://sc.30120.org/fpgis/secure/Login.aspx?ReturnUrl=\%2ffpgis\%2f) was used to obtain the distribution of Dendrolimus houi Lajonquiere in Sichuan Province from 2010 to 2018. Forestry workers in each county investigated the occurrence of Dendrolimus houi Lajonquiere and uploaded the statistics to the network platform, which was updated 
annually. Through screening and elimination of duplicate sites, 70 distribution sites were ultimately obtained. Query the latitude, longitude and altitude of each site through Google Map, and arrange them by the name of the species, longitude and latitude, and import ArcGIS. And use the distribution Fitter toolbox in Matlab to fit the distribution of latitude and longitude to obtain the distribution law of latitude and longitude.

\section{Environment variable factor}

Environment variables: climate data and elevation data mainly come from the global climate interpolation data network (http://www.worldclim.org/). From this network, 28 types of environmental data were selected, including 25 climate factors (Bio01-Srad) and 3 terrain factors (Alt, Slo, Asp). The altitude data (Alt), slope (Slo) and aspect (Asp) were extracted using ArcGIS. These factors were analyzed in detail using a spatial resolution of $30 \mathrm{~s}$ (precision for $1 \mathrm{~km} \times 1 \mathrm{~km}$ ) from the years of 1970 2000 (Table 1). The global climate interpolation network WorldClim was downloaded to convert the 28 climate variable factors obtained via ArcGIS to ASC format.

Table 1. List of 28 environment variables

\begin{tabular}{|c|c|c|}
\hline Variable data & Description & Unit \\
\hline Bio1 & Annual mean temperature & ${ }^{\circ} \mathrm{C}$ \\
\hline Bio2 & Mean diurnal range & ${ }^{\circ} \mathrm{C}$ \\
\hline Bio3 & Isothermality & - \\
\hline Bio4 & Temperature seasonality & $\mathrm{C}$ of $\mathrm{V}$ \\
\hline Bio5 & Max temperature of warmest month & ${ }^{\circ} \mathrm{C}$ \\
\hline Bio6 & Min temperature of coldest month & ${ }^{\circ} \mathrm{C}$ \\
\hline Bio7 & Temperature annual range & ${ }^{\circ} \mathrm{C}$ \\
\hline Bio8 & Mean temperature of wettest quarter & ${ }^{\circ} \mathrm{C}$ \\
\hline Bio9 & Mean temperature of driest quarter & ${ }^{\circ} \mathrm{C}$ \\
\hline Bio10 & Mean temperature of warmest quarter & ${ }^{\circ} \mathrm{C}$ \\
\hline Bio11 & Mean temperature of coldest quarter & ${ }^{\circ} \mathrm{C}$ \\
\hline Bio12 & Annual precipitation & $\mathrm{mm}$ \\
\hline Bio13 & Precipitation of wettest month & $\mathrm{mm}$ \\
\hline Bio14 & Precipitation of driest month & $\mathrm{mm}$ \\
\hline Bio15 & Precipitation seasonality & $\mathrm{C}$ of $\mathrm{V}$ \\
\hline Bio16 & Precipitation of wettest quarter & $\mathrm{mm}$ \\
\hline Bio17 & Precipitation of driest quarter & $\mathrm{mm}$ \\
\hline Bio18 & Precipitation of warmest quarter & $\mathrm{mm}$ \\
\hline Bio19 & Precipitation of coldest quarter & $\mathrm{mm}$ \\
\hline Prec & Precipitation & $\mathrm{mm}$ \\
\hline $\operatorname{Tmax}$ & Maximum temperature & ${ }^{\circ} \mathrm{C}$ \\
\hline Tmin & Minimum temperature & ${ }^{\circ} \mathrm{C}$ \\
\hline Tavg & Average temperature & ${ }^{\circ} \mathrm{C}$ \\
\hline Wind & Wind speed & $\mathrm{m} \mathrm{s}^{-1}$ \\
\hline Srad & Solar radiation & $\mathrm{kJ} \mathrm{m}^{-2}$ day $^{-1}$ \\
\hline Slo & Slope & $\%$ \\
\hline Asp & Aspect & $\circ$ \\
\hline Alt & Altitude & $\mathrm{m}$ \\
\hline
\end{tabular}




\section{openModeller modelling}

openModeller (version 1.5.1; http://openmodeller.sourceforge.net/) is used to predict the potential distribution of Dendrolimus houi Lajonquiere in Sichuan. The openModeller version (1.1.0) includes the following algorithms: AquaMaps, ANN (Artificial Neural Networks), Bioclim, CSM (Climate Space Model), ENFA (Environment Niche), ES (Envelope Score), ED (Environment Distance), GARP, MaxEnt (Maximum Entropy), NM (Niche Mosaic) and SVM. BIOCLIM and Envelope Scores are classic "climate envelope models" that use the minimum and maximum observations of each environmental variable to define the bioclimatic range. The Climate Spatial Model is a principal component-based algorithm that compares the observed environment with the background data of the study area. GARP is an algorithm based on genetic rules that creates niche models to describe the environmental conditions that the species should be able to maintain the population. Machine learning models are non-parametric, flexible and variable regression models. They are also the most widely used SDM model, including Artificial Neural Network (ANN), MaxEnt and Support Vector Machine.

Input the species distribution data of Dendrolimus houi Lajonquiere into openModeller, the threshold is set to $30 \%$, and other specific parameters are set to default values (Santana et al., 2008). The 7 distribution models of Artificial neural network, Bioclim, GARP, Climate Spatial Model, Envelope Score, Maximum Entropy and SVM in openModeller are used to simulate the potential distribution area of Dendrolimus houi Lajonquiere in Sichuan, and the fitting results are divided into four levels: high potential area $(0.5 \leq \mathrm{P})$, good potential area $(0.3 \leq \mathrm{P}<0.5)$, moderate potential area $(0.1 \leq \mathrm{P}<0.3)$, and least potential area $(\mathrm{P}<0.1)$. The AUC value (the area under the receiver operating characteristic curve ROC) is widely used to evaluate the accuracy of the model (Shabani et al., 2018). Therefore, models were examined by calculating the AUC in the ROC curve (values of 0.5 0.6 indicate failure, 0.6 0.7 indicate poor, 0.7 0.8 indicate worse, 0.8 0.9 indicate better, and 0.9 1.0 indicate good) to determine the models' accuracy (Phillips et al., 2006).

\section{Results}

\section{Occurrence in Sichuan Province}

From 2010 to 2018, the main affected areas of Dendrolimus houi Lajonquiere in Sichuan Province were concentrated in the northeastern plains of Sichuan. Chengdu has the most distribution points among all cities, with a total of 12 points. The distribution range of longitude includes $101.5^{\circ} \mathrm{E} \sim 107.7^{\circ} \mathrm{E}$, and the distribution range of latitude includes $27.1^{\circ} \mathrm{N} \sim 32.6^{\circ} \mathrm{N}$. Using the probability density toolbox of Matlab to analyze the latitude and longitude of the distribution of Dendrolimus houi Lajonquiere, it is found that it conforms to the generalized extreme value distribution law, showing the characteristics of skewed distribution. The peak frequency of occurrence is $104.5^{\circ} \mathrm{E}$ to $106^{\circ} \mathrm{E}$ in longitude and $30^{\circ} \mathrm{N}$ to $31^{\circ} \mathrm{N}$ in latitude (Fig. 2). At the same time, using the density analysis tool in ArcGIS to analyze the nuclear density of the distribution sites, it is found that Chengdu City, Deyang City, Nanchong City, Mianyang City, Guangyuan City, Luzhou City, Dazhou City occur more frequently. Rarely, the outbreaks occurred in other regions with a relatively narrow range of occurrence. The distribution points were the most in 2012 and 2013, while the distribution points were the least in 2011 and 
2018. The overall trend was cyclical changes, which were inseparable from changes in climate factors (Fig. 3).

\section{Environmental variable factor division}

In order to eliminate the influence of multicollinearity on the accuracy of the model and select variables with higher value to the model, the correlation coefficient of 28 environmental variables was analyzed using the band set statistical method of ArcGIS, and two environmental factors with a correlation greater than 0.8 were analyzed $(|r|>0.8)$. Screen, choose one as the key factor to keep. The selected variables include wind speed in October (Wind10), average precipitation in July (Prec7), Temperature Seasonality (Bio4), Precipitation Seasonality (Bio15), solar radiation in March (Srad3), average precipitation in February (Prec2), solar radiation in May (Srad5) (as seen from Table 2).

Table 2. The correlation coefficient analysis of 7 important environment variables

\begin{tabular}{c|c|c|c|c|c|c|c}
\hline Variable & Wind10 & Prec07 & Bio04 & Bio15 & Srad03 & Prec02 & Srad05 \\
\hline Wind10 & 1 & & & & & & \\
Prec7 & 0.09616 & 1 & & & & & \\
Bio4 & -0.70683 & -0.23695 & 1 & & & & \\
Bio15 & -0.7472 & 0.00952 & 0.65299 & 1 & & & \\
Srad3 & 0.0374 & -0.32586 & 0.21193 & 0.30052 & 1 & & \\
Prec2 & -0.59378 & -0.54236 & 0.57145 & 0.76534 & 0.3256 & 1 & \\
Srad5 & 0.6625 & 0.30775 & -0.55405 & -0.64073 & -0.56646 & -0.57993 & 1 \\
\hline
\end{tabular}

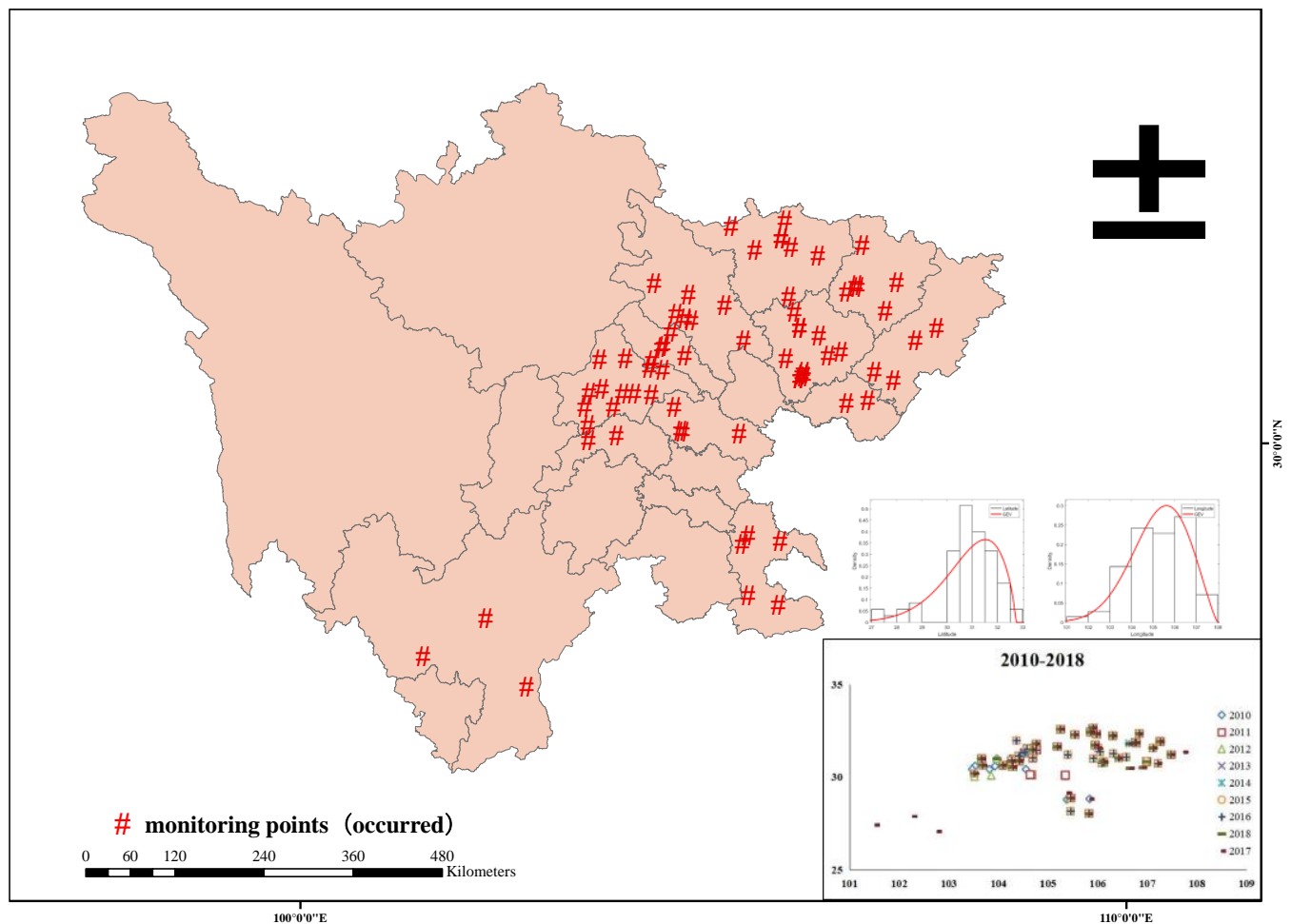

Figure 2. The map shows the occurrence records of Dendrolimus houi Lajonquiere specimens from 2010 to 2018 and the regularity of their occurrence frequency in latitude and longitude 

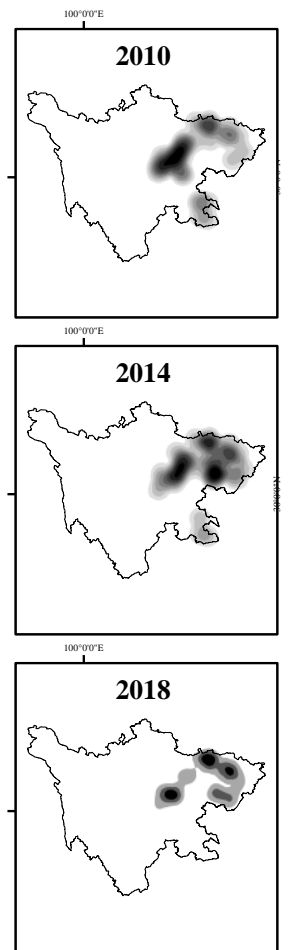
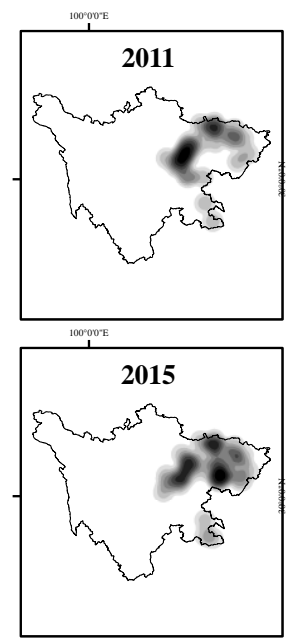

2010-2018

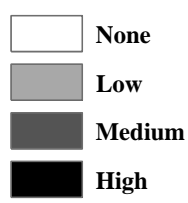

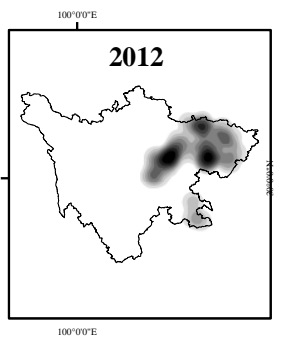
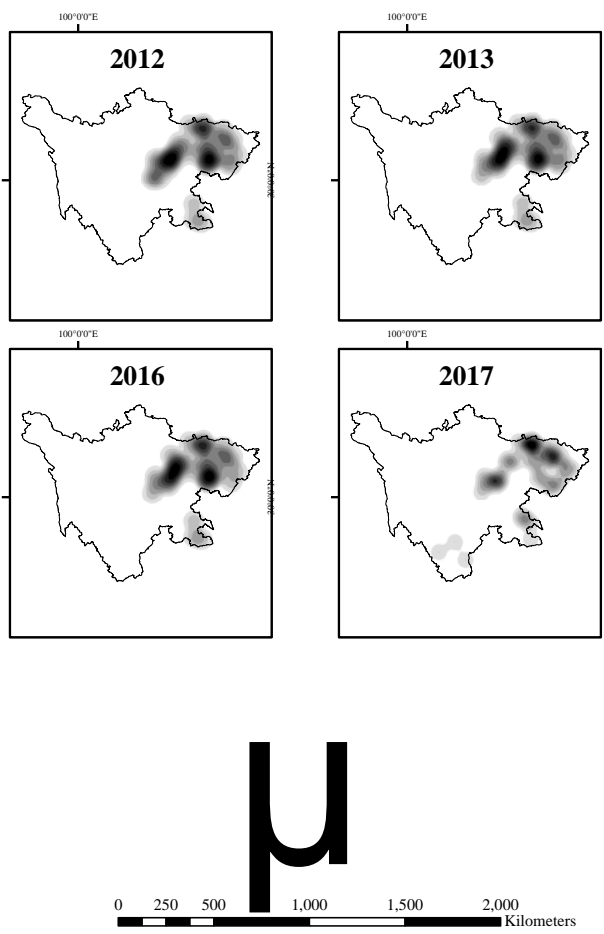

Figure 3. Kernel density of the Dendrolimus houi Lajonquiere from 2010 to 2018. White indicates that there is no concentration in the center, gray indicates that the range of the species is small, light black indicates the center concentration is medium, and dark black indicates the highest concentration in the center

\section{Choice of species distribution model}

Bio4, Bio15, Prec2, Prec7, Srad3, Srad5 and Wind10 were used as environment layers. Seven species distribution models, Artificial Neural Network, Bioclim, GARP, Climate Space Model, Envelope Score, Maximum Entropy and SVM, were used to simulate the distribution results. The ROC curve was used to determine the accuracy of the model. The experimental results are as follows.

The AUC values were between 0.82 and 0.9 , and the accuracy was high. From high to low: SVM (0.9) > GARP = Maximum Entropy (0.88) > Artificial Neural Network $(0.85)>$ Bioclim (0.84) > Envelope Score (0.83) > Climate Space Model (0.82). Among them, the SVM model had the highest AUC value of 0.9, with higher accuracy and stronger credibility (as seen from Table 3).

Table 3. Accuracy, AUC, sensitivity and omission error of 7 species distribution model

\begin{tabular}{c|c|c|c|c}
\hline Algorithm & Accuracy & AUC & Sensitivity & Omission error \\
\hline Artificial Neural Network & 80 & 0.85 & 0.8 & 0.0143 \\
Bioclim & 100 & 0.84 & 1 & 0 \\
Climate Space Model & 84.3 & 0.82 & 0.84 & 0.2 \\
Envelope Score & 100 & 0.83 & 1 & 0 \\
GARP & 94.3 & 0.88 & 0.94 & 0.0571 \\
Maximum Entropy & 98.6 & 0.88 & 1 & 0.0143 \\
SVM & 95.7 & 0.9 & 0.96 & 0.0571 \\
\hline
\end{tabular}




\section{Division of potential areas}

The distribution results of the 7 species distribution models, Artificial Neural Network, Bioclim, GARP, Climate Space Model, Envelope Score, Maximum Entropy and SVM, were imported into ArcGIS (Fig. 4). The simulated distribution area was divided into four levels by using the natural discontinuity method (Table 4 ). There were 4 types of high potential area $(0.5 \leq \mathrm{P})$, good potential area $(0.3 \leq \mathrm{P}<0.5)$, moderate potential area $(0.1 \leq \mathrm{P}<0.3)$, and least potential area $(\mathrm{P}<0.1)$. The average total suitable area simulated by the 7 models is $253839.59 \mathrm{~km}^{2}$, occupying $52.23 \%$ of the area of Sichuan. Among them, the low, medium and high suitable areas are $96227.54 \mathrm{~km}^{2}, 66062.81 \mathrm{~km}^{2}$ and $91549.23 \mathrm{~km}^{2}$, respectively.
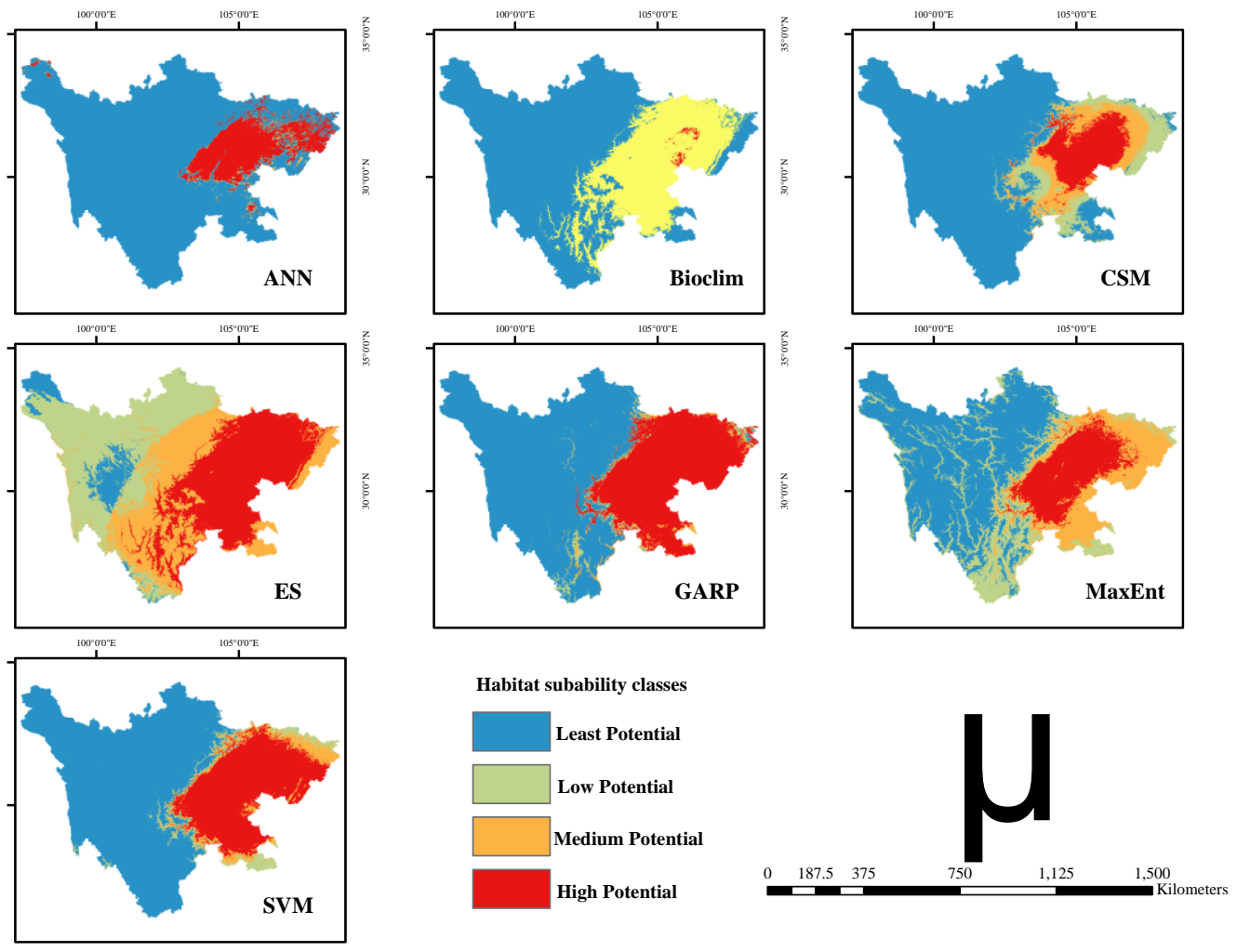

Figure 4. The potential distribution area of Dendrolimus houi Lajonquiere in Sichuan area simulated by 7 species distribution models. Different colors represent different levels of habitat suitability: red indicates high suitability, with a probability greater than 0.5. Yellow indicates moderate suitability, with a probability of 0.4-0.5, green indicates low suitability, with a probability of 0.1-0.3, white indicates inappropriate, with a probability of less than 0.1

The potential area for the Dendrolimus houi Lajonquiere was mainly concentrated in the northeastern plain of the Sichuan Basin. The high potential area was mainly concentrated in Chengdu, Dujiangyan, Bazhong, Suining, Mianyang, Guangyuan, Deyang City, and Nanchong City. The good potential area was mainly concentrated in Ziyang City, Meishan City, Neijiang City, Zigong City, and Yibin City. The moderate potential area was mainly concentrated in Leshan City, Ya'an City, Luzhou City and South of Liangshan Yi Autonomous Prefecture. The unhealthy areas were mainly concentrated in Ganzi Tibetan Autonomous Prefecture, Aba Tibetan Autonomous 
Prefecture, and Liangshan Yi Autonomous Prefecture. Comparing the temporal and spatial patterns of Dendrolimus houi Lajonquiere in Sichuan Province from 2010 to 2018, the simulation results were essentially consistent. Thus, it can be proved that the SVM model is the best model for the distribution of Dendrolimus houi Lajonquiere in the Sichuan area.

Table 4. The suitable area and proportion of Dendrolimus houi Lajonquiere in Sichuan

\begin{tabular}{|c|c|c|c|c|c|c|c|c|}
\hline \multirow[t]{2}{*}{ Algorithm } & \multicolumn{2}{|c|}{ Least potential $\left(\mathbf{k m}^{2}\right)$} & \multicolumn{2}{|c|}{$\begin{array}{c}\text { Low potential area } \\
\left(\mathbf{k m}^{2}\right)\end{array}$} & \multicolumn{2}{|c|}{$\begin{array}{l}\text { Medium potential area } \\
\left(\mathbf{k m}^{2}\right)\end{array}$} & \multicolumn{2}{|c|}{$\begin{array}{c}\text { High potential area } \\
(\mathbf{k m} 2)\end{array}$} \\
\hline & Rate (\%) & Area $\left(\mathbf{k m}^{2}\right)$ & Rate $(\%)$ & Area $\left(\mathbf{k m}^{2}\right)$ & Rate (\%) & Area $\left(\mathrm{km}^{2}\right)$ & Rate (\%) & Area $\left(\mathrm{km}^{2}\right)$ \\
\hline Artificial Neural Network & $83.78 \%$ & 407189.3 & $1.36 \%$ & 6612.5 & $0.95 \%$ & 4619.7 & $13.91 \%$ & 67578.5 \\
\hline Bioclim & $0.00 \%$ & 0 & $67.14 \%$ & 326317.1 & $32.42 \%$ & 157570.5 & $0.43 \%$ & 2112.4 \\
\hline Climate Space Model & $68.57 \%$ & 333241.1 & $10.41 \%$ & 50569.3 & $9.92 \%$ & 48232.5 & $11.10 \%$ & 53957.1 \\
\hline Envelope Score & $6.62 \%$ & 32152.5 & $33.13 \%$ & 160992.2 & $27.40 \%$ & 133165.1 & $32.86 \%$ & 159690.2 \\
\hline GARP & $62.70 \%$ & 304734.7 & $2.84 \%$ & 13788.9 & $2.29 \%$ & 11149.5 & $32.17 \%$ & 156326.8 \\
\hline Maximum Entropy & $48.29 \%$ & 234709.4 & $19.28 \%$ & 93698.7 & $16.74 \%$ & 81338.7 & $15.69 \%$ & 76253.2 \\
\hline SVM & $64.42 \%$ & 313095.8 & $4.45 \%$ & 21614.1 & $5.42 \%$ & 26363.7 & $25.71 \%$ & 124926.4 \\
\hline Average & $47.77 \%$ & 232160.4 & $19.8 \%$ & 96227.54 & $13.59 \%$ & 66062.81 & $18.84 \%$ & 91549.23 \\
\hline
\end{tabular}

\section{Climate factor variable statistics}

Using the Spatial Analyst function in ArcGIS, the niche parameters of the seven contribution factors in the distribution of the different fitness levels were extracted, including the range, maximum, minimum, average, and standard deviation. The results show that among the different grades of suitable regions, the changes of the leading environmental variable factors (Bio4, Bio15, Prec2, Prec7, Srad3, Srad5 and Wind10) showed the same trend: the range gradually decreased, and the standard deviation gradually increased and then decreased, with less variation. Comprehensive analysis showed that Dendrolimus houi Lajonquiere has a wide tolerance range for climatic factors. The range occurred when the temperature seasonality was 619.6 810.9, the precipitation seasonality was 162.3 103.2, the average precipitation in February was 6 29 $\mathrm{mm}$, he average precipitation in July was 167 367 $\mathrm{mm}$, the solar radiation in March was 9001 12123 $\mathrm{kJ} \mathrm{m}^{-2}$ day $^{-1}$ and the solar radiation in May was $14540 \sim 16964 \mathrm{~kJ} \mathrm{~m}^{-2}$ day $^{-1}$, the wind speed in October was $0.8 \sim 1.8 \mathrm{~m} \mathrm{~s}^{-1}$ (Table 5).

\section{Discussion}

This paper analyzes the distribution points of Dendrolimus houi Lajonquiere by using ArcGIS and Matlab. It is found that Dendrolimus houi Lajonquiere has a high frequency of distribution in the northeastern plains of Sichuan. The distribution range of Dendrolimus houi Lajonquiere spans 5 latitudes and longitudes, with a concentration of $104.5^{\circ} \mathrm{E}$ to $106^{\circ} \mathrm{E}$, a latitude distribution of $31^{\circ} \mathrm{N}$ to $33^{\circ} \mathrm{N}$. It is less distributed in other regions, such as northern and western regions, which is inseparable from the distribution of host plants. Insect distribution changes with changes in latitude, longitude, are also limited by host plants and environmental factors (Xin et al., 2019). Dendrolimus houi Lajonquiere eat cypress leaves in Sichuan, and Sichuan cypress is mainly distributed in the northeastern plain at an altitude of 350-700 $\mathrm{m}$ ( $\mathrm{Li}$ et al., 2017). This is also an important reason affecting the distribution of Dendrolimus houi Lajonquiere in Sichuan. The distribution space overlaps between the two, showing a 
strong saliency relationship, which reasonably explains the extreme distribution of the Dendrolimus houi Lajonquiere.

Table 5. Statistical analysis of variables in different suitable classes of Dendrolimus houi Lajonquiere from SVM model

\begin{tabular}{|c|c|c|c|c|c|c|c|c|c|}
\hline \multirow[b]{2}{*}{ Variables } & \multicolumn{2}{|c|}{ Least potential } & \multicolumn{2}{|c|}{ Low potential } & \multicolumn{2}{|c|}{ Medium potential } & \multicolumn{2}{|c|}{ High potential } & \multirow[b]{2}{*}{ Unit } \\
\hline & Range & $\begin{array}{c}\text { Mean } \\
\pm \text { Std }\end{array}$ & Range & $\begin{array}{c}\text { Mean } \\
\pm \text { Std }\end{array}$ & Range & $\begin{array}{c}\text { Mean } \\
\pm \text { Std }\end{array}$ & Range & $\begin{array}{c}\text { Mean } \\
\pm \text { Std }\end{array}$ & \\
\hline Bio4 & $439.4 \sim 887.2$ & $\begin{array}{l}636.7 \\
\pm 85.0\end{array}$ & $499.3 \sim 817.4$ & $\begin{array}{l}703.3 \\
\pm 57.9\end{array}$ & 599.9 821.1 & $\begin{array}{l}739.6 \\
\pm 45.4\end{array}$ & $619.6 \sim 810.9$ & $\begin{array}{l}733.7 \\
\pm 30.4\end{array}$ & $\mathrm{C}$ of $\mathrm{V}$ \\
\hline Bio15 & $70.1 \sim 109.8$ & $\begin{array}{r}89.9 \\
\pm 6.5 \\
\end{array}$ & 63.1 95.8 & $\begin{array}{l}78.1 \\
\pm 7.9 \\
\end{array}$ & $63.1 \sim 98.3$ & $\begin{array}{r}78.6 \\
\pm 9.4 \\
\end{array}$ & $62.3 \sim 103.2$ & $\begin{array}{c}85.8 \\
\pm 10.5 \\
\end{array}$ & $\mathrm{C}$ of $\mathrm{V}$ \\
\hline Prec2 & $2 \sim 20$ & $\begin{array}{c}7.9 \\
\pm 2.3\end{array}$ & $4 \sim 34$ & $\begin{array}{l}14.2 \\
\pm 3.6\end{array}$ & $6 \sim 29$ & $\begin{array}{l}15.0 \\
\pm 4.3\end{array}$ & $6 \sim 29$ & $\begin{array}{l}16.3 \\
\pm 5.0\end{array}$ & $\mathrm{~mm}$ \\
\hline Prec 7 & $95 \sim 236$ & $\begin{array}{l}144.3 \\
\pm 25.1 \\
\end{array}$ & $110 \sim 239$ & $\begin{array}{l}175.5 \\
\pm 19.7 \\
\end{array}$ & $156 \sim 367$ & $\begin{array}{l}196.1 \\
\pm 17.7 \\
\end{array}$ & $167 \sim 367$ & $\begin{array}{l}232.9 \\
\pm 36.0 \\
\end{array}$ & $\mathrm{~mm}$ \\
\hline Srad3 & $10174 \sim 17299$ & $\begin{array}{l}13722.5 \\
\pm 1120.3 \\
\end{array}$ & $9909 \sim 16172$ & $\begin{array}{c}11795.3 \\
\pm 908.6 \\
\end{array}$ & $9744 \sim 12639$ & $\begin{array}{c}11473.9 \\
\pm 463.1 \\
\end{array}$ & $9001 \sim 12123$ & $\begin{array}{c}10874.1 \\
\pm 625.3\end{array}$ & $\mathrm{~kJ} \mathrm{~m}^{-2} \mathrm{day}^{-1}$ \\
\hline Srad5 & $15291 \sim 20412$ & $\begin{array}{c}17322.3 \\
\pm 984.8\end{array}$ & $14902 \sim 18639$ & $\begin{array}{l}15894 \\
\pm 613.4\end{array}$ & $14866 \sim 16936$ & $\begin{array}{c}15873.9 \\
\pm 526.7\end{array}$ & $14540 \sim 16964$ & $\begin{array}{c}15356.4 \\
\pm 439.6\end{array}$ & $\mathrm{~kJ} \mathrm{~m}^{-2} \mathrm{day}^{-1}$ \\
\hline Wind 10 & $1 \sim 5.1$ & $\begin{array}{c}2.6 \\
\pm 0.7\end{array}$ & $0.9 \sim 8.8$ & $\begin{array}{c}1.6 \\
\pm 0.4\end{array}$ & $0.9 \sim 2.3$ & $\begin{array}{c}1.3 \\
\pm 0.2\end{array}$ & $0.8 \sim 1.8$ & $\begin{array}{c}1.1 \\
\pm 0.2\end{array}$ & $\mathrm{~m} \mathrm{~s}^{-1}$ \\
\hline
\end{tabular}

Studies have shown that terrestrial insects are sensitive to changes in water and temperature; thus, climatic factors have played an important role in the life cycle and geographical distribution of insects (Kingsolver et al., 2011). The occurrence of Dendrolimus houi Lajonquiere is concentrated in the northeastern plains of the Sichuan Basin and has expanded in scope over time, in a manner that is inseparable from the climate change caused by global warming. Changes in precipitation and temperature have a significant relationship with the occurrence area of Dendrolimus houi Lajonquiere. The 7 factors screened in this study were Bio4, Bio15, Prec2, Prec7, Srad3, Srad5 and Wind10. With reference to the former study (Zhao and Liu, 2007), the highest temperature in December, precipitation throughout the year and the duration of light were considered important climate indicators. At the same time, the life history of Dendrolimus houi Lajonquiere was evaluated. In April, Dendrolimus houi Lajonquiere are young larvae, and their resistance is poor. The larvae will die if the temperature is too high or too low; September is the high incidence period of Dendrolimus houi Lajonquiere cocooning pupae and feathering adults. Excessive precipitation will cause mature larvae to fail to weave on the branches and leaves of trees or shrubs, leading to the mechanical death of pupae or adults. December is the wintering period of eggs. Too low a temperature causes a delay or failure of larval hatching (He et al., 2018; Zhou et al., 2019). This proves that the six climate factors have strong credibility and can be used as important reference indicators for early warning and monitoring of the occurrence of Dendrolimus houi Lajonquiere.

With reference to related studies, the use of the AUC value of the ROC curve area to evaluate the precise value of the species distribution model has been widely used (Xu et al., 2015). This paper uses Artificial Neural Network, Bioclim, GARP, Climate Space Model, Envelope Score, Maximum Entropy and SVM to simulate the suitable distribution area of Dendrolimus houi Lajonquiere in Sichuan. AUC prediction results ranging from 0.82 to 0.9 were obtained, among which the AUC value of the SVM model was the highest at 0.9. As a supervised machine learning language, the SVM 
model is often used in many fields, such as pattern recognition and regression analysis, but it lacks application experience in ecological modeling (Hoang et al., 2010). Due to their robustness, SVM can correlate the distribution pattern of organisms with abiotic characteristics, thus providing reliable predictions for organisms (Keerthi et al., 2010). In the research for this paper, the SVM model had the highest accuracy value, and it is the most suitable species distribution model compared with the geographical distribution pattern of Dendrolimus houi Lajonquiere in Sichuan.

Comprehensive analysis of the niche parameters of 7 key climate factors found that the Dendrolimus houi Lajonquiere especially liked a warm and humid environment and had a wide temperature tolerance range. The range occurs when the average precipitation in September is $102 \sim 190 \mathrm{~mm}$, the average precipitation in February is 6$29 \mathrm{~mm}$, the minimum temperature in February is $1.4 \sim 12.2^{\circ} \mathrm{C}$, the isotherm is $23.1 \sim 44.8$, the average temperature in April is $15.7 \sim 24.4{ }^{\circ} \mathrm{C}$, and the maximum temperature in December is $8.8 \sim 19.3{ }^{\circ} \mathrm{C}$. The range of suitable climate factors for the Dendrolimus houi Lajonquiere provides an important reference for related prevention and management work. When the temperature and precipitation reach suitable living conditions, it is necessary to strengthen the monitoring and early warning of the forest to prevent a large outbreak of Dendrolimus houi Lajonquiere.

Many studies have shown that invasive alien species will be difficult to completely eradicate after entering their habitats and will cause large losses in the local ecological environment (Koyama et al., 2004; Kong et al., 2008). The distribution trend of Dendrolimus houi Lajonquiere was analyzed through the spatial distribution pattern of Dendrolimus houi Lajonquiere and the map of environmental factors. Central and southern Sichuan are potential areas for future invasion by Dendrolimus houi Lajonquiere; in particular, the border between Sichuan and Yunnan has become a hidden danger and shows evidence of radiation. Among the involved factors, transportation has played a role that cannot be ignored. The breeding method of Dendrolimus houi Lajonquiere involves the spawning and hatching of adult worms. The flight distance of adult worms is limited, and it is difficult to achieve such a rapid spread. The continuous construction of a large number of infrastructures has accelerated the conversion of logistics between cities and has indirectly facilitated the spread of Dendrolimus houi Lajonquiere. Adults invade other urban areas by laying eggs on transportation vehicles or untested seedlings and trees, causing serious disasters.

This paper uses species distribution models to simulate the suitability distribution of Dendrolimus houi Lajonquiere in Sichuan Province of China. The simulation results are good, but there are still some limitations. First of all, the time span of climate factors used in this study is from 1970 to 2000 . Failure to use future climate data will cause deviations in the prediction of suitable areas for Dendrolimus houi Lajonquiere. Secondly, in the actual living environment of species, host plants, interspecies competition, human interference, extreme climate changes, etc. will all have an impact on the potential distribution of predicted species.

\section{Conclusion}

The northeastern plains of Sichuan (longitudes $104.5^{\circ} \mathrm{E}$ to $106^{\circ} \mathrm{E}$, latitude $31^{\circ} \mathrm{N}$ to $33^{\circ} \mathrm{N}$ ) are concentrated high-explosive areas, which are inseparable from the local topographic and climatic conditions. The terrain of the plain in northeastern Sichuan is flat, the climate is a subtropical monsoon climate, warm and humid, with a few extreme 
climates. At the same time, the large number of cypresses in northeastern Sichuan provides a rich source of food for Dendrolimus houi Lajonquiere. Comprehensive analysis shows that the core idea for the control of Dendrolimus houi Lajonquiere is no longer the single control of pine caterpillars but rather the formation of a "ForestDendrolimus houi Lajonquiere" ecosystem linkage and the use of ecological principles and probability statistics to analyze and solve the problems. Knowledge of the key climate factors of pine caterpillars, reasonable planning of prevention and control areas, strengthening forestry quarantine law enforcement, and establishing accurate species distribution models can not only effectively prevent Dendrolimus houi Lajonquiere from destroying forests but also avoid economic waste and destruction to the environment caused by blind pollution control. In future studies, while adding future impact factor data Therefore, it is necessary to thoroughly explore the impact of global warming on the distribution of Dendrolimus houi Lajonquiere, so as to make the prediction results more accurate and reliable.

Disclosure statement. The authors report no conflict of interests.

\section{REFERENCES}

[1] Beaumont, L. J., Hughes, L., Poulsen, M. (2005): Predicting species distributions: use of climatic parameters in bioclim and its impact on predictions of species' current and future distributions. - Ecological Modelling 186(2): 251-270.

[2] Drake, J. M., Guisan, R. A. (2006): Modelling ecological niches with support vector machines. - Journal of Applied Ecology 43(3): 424-432.

[3] Duan, X. F., Wang, X. Q., Li, P. W., Li, P. W., Peng, P. (2015): Research progress on the effects of several environmental factors on adapt ability of insects. - Chinese Agricultural Science Bulletin 31(14): 79-82.

[4] Ghareghan, F., Ghanbarian, G., Pourghasemi, H. R., Safaeian, R. (2020): Prediction of habitat suitability of Morina persica L. species using artificial intelligence techniques. Ecological Indicators 112: 106096.

[5] Gou, W. H., Shen, Y. X., Chai, S. Q. (2003): Research progress on monitoring and management of Dendrolinus houi Lajonquière in China. - Forest Pest and Disease 22(5): 28-31.

[6] Han, X., Lu, C. D., Scott, M. G., Zheng, J. X., Wu, S. Q., Zhang, F. P., Liang, G. H. (2019): Characterization of Dendrolimus houi Lajonquiere (Lepidoptera: Lasiocampidae) transcriptome across all life stages. - Insects 10(12): 442.

[7] He, X., Zou, X. M., Shang, H. Y., He, H. G., Yuan, S. B. (2018): The occurrence regularity and biocontrol research of dendrolimus houi lajonquiere in cypress forest of Guang'an. - Journal of China West Normal University (Natural Sciences) 39(2): 132136.

[8] Hirzel, A. H., Guisan, A. (2002): Which is the optimal sampling strategy for habitat suitability modelling. - Ecological Modelling 157(2-3): 331-341.

[9] Hoang, T. H., Lock, K., Mouton, A., Goethals, P. L. M. (2010): Application of classification trees and support vector machines to model the presence of macroinvertebrates in rivers in Vietnam. - Ecological Informatics 5(2): 140-146.

[10] Hua, Y., Lu, C. D., Shi, Y. F., He, H., Han, X. H., Lin, H. Y., Zhang, F. P., Liang, G. H. (2019): Research advances in Dendrolimus houi Lajonquiere of China. - World Forestry Research 32(4): 62-68.

[11] Keerthi, S. S., Shevade, S. K., Bhattacharyya, C. (2010): Improvements to Platt's SMO algorithm for SVM classifier design. - Neural Computation 13(3): 637-649. 
[12] Khanum, R., Mumtaz, A. S., Kumar, S. (2013): Predicting impacts of climate change on medicinal asclepiads of Pakistan using maxent modeling. - Acta Oecologica 49: 23-31.

[13] Kingsolver, J. G., Woods, H. A., Buckley, L. B., Potter, K. A., MacLean, H. J., Higgins, J. K. (2011): Complex life cycles and the responses of insects to climate change Integr. Integrative and Comparative Biology 51(5): 719-732.

[14] Kong, L. B., Lin, W., Li, Z. H., Wan, F. H., Wang, Z. 1., Huang, G. S. (2008): A predication of potential geographic distribution of melon fruit based on CLIMEX and DIVA-GIS. - Journal of Plant Protection 2: 148-154.

[15] Koyama, J., Kakinohana, H., Miyatake, T. (2004): Eradication of the melon fly, Bactrocera cucurbitae, in Japan: importance of behavior, ecology, genetics, and evolution. - Annual Review of Entomology 49(49): 331-349.

[16] Li, W., Zhong, G. H. (2013): Occurrence and Prevention and Control of Dendrolmus houi Lajonquere. - Ningxia Journal of Agriculture and Forestry Science and Technology 54(5): 76-77.

[17] Li, R. H., Wang, F., Zhou, L. J., Liu, B. (2017): Research on the distribution and productivity of Cupressus funebris in Sichuan Province. - Sichuan Forestry Exploration and Design 1: 22-26 + 57

[18] Liu, X. Z. (2006): Study on biological characteristics and its integrated control of Dendrolimus latipenis. - Journal of Southwest Forestry College 26(3): 52-54.

[19] Mukul, S. A., Alamgir, M., Sohel, M. S. I., Pert, P. L., Herbohn, J., Turton, S. M., Khan, M. S. I., Munim, S. A., Ali, Reza, A. H. M., Laurance, W. F. (2019): Combined effects of climate change and sea-level rise project dramatic habitat loss of the globally endangered Bengal tiger in the Bangladesh Sundarbans. - Science of The Total Environment 663(1): 830-840.

[20] Oyafuso, Z. S., Drazen, J. C., Moore, C. H., Franklin, E. C. (2017): Habitat-based species distribution modelling of the Hawaiian deepwater snapper-grouper complex. - Fisheries Research 195: 19-27.

[21] Padalia, H., Srivastava, V., Kushwaha, S. P. S. (2014): Modeling potential invasion range of alien invasive species, Hyptis suaveolens (L.) Poit. in India: comparison of maxent and garp. - Ecological Informatics 22: 36-43.

[22] Phillips, S. J., Anderson, R. P., Schapire, R. E. (2006): Maximum entropy modeling of species geographic distributions. - Ecological Modelling 190(3): 231-259.

[23] Santana, F. S., Siqueira, M. F. D., Saraiva, A. M., Correa, P. L. P. (2008): A reference business process for ecological niche modelling. - Ecological Informatics 3(1): 75-86.

[24] Sastawa, B. M., Lawan, M., Maina, Y. T. (2002): Management of insect pests of soybean: effects of sowing date and intercropping on damage and grain yield in the Nigerian Sudan savanna. - Crop Prot 23(2): 155-161.

[25] Shabani, F., Tehrany, M. S., Solhjouy-Fard, S., Kumar, L. (2018): A comparative modeling study on nonclimatic and climatic risk assessment on Asian tiger mosquito (Aedes albopictus). - Peerj 6: e4474.

[26] Sobek-Swant, S., Kluza, D. A., Cuddington, K., Lyons, D. B. (2012): Potential distribution of emerald ash borer: what can we learn from ecological niche models using maxent and garp? - Forest Ecology and Management 281: 23-31.

[27] Song, Y. S., Dong, Y. Q., Cui, D. Y., Yue, F. Z., Zhu, N. B., Bai, H. Y. (2019): Species analysis of forest pest in China V. Insect. - Forest Pest and Disease 38(1): 26-30.

[28] Xin, B., Dang, Y. Q., Wang, X. Y., Yang, Z. Q. (2019): Mechanisms and influential factors of southern limits in insects. - Acta Ecologica Sinica 39(24): 362-369.

[29] Xu, G. L. (2008): Research advances on Dendrolimus houi in Yunnan Province. - Journal of Southwest Forestry College 28(3): 42-44 + 50.

[30] Xu, Z. L., Peng, H. H., Peng, S. Z. (2015): The development and evaluation of species distribution models. - Acta Ecologica Sinica 35(2): 557-567. 
[31] Yang, H., Shen, Y., Deng, S. S., Tang, Y. L., Zhan, M. K., Wang, J. (2017): Summary on IPM Against Dendrolimus houi Lajonquiere. - Biological Disaster Science 40(4): 231234.

[32] Yin, A. L., Chuan, R. F., Xu, G. L. (2002): A study on the biological characteristics of Dendrolimus houi. - Journal of Southwest Forestry College 22(4): 53-55.

[33] Yu, X. W., Liu X. Y. (2001): Review of research methods on spatial pattern of insect population. - Journal of Northwest Forestry University (3): 83-87 + 90 .

[34] Yu, H., Cooper, A. R., Infante, D. M. (2020): Improving species distribution model predictive accuracy using species abundance: application with boosted regression trees. Ecological Modelling 432: 109202.

[35] Zhang, W. (2015): Spatial distribution pattern and sampling technique for larvae of Dendrolimus houi. - Protection Forest Science and Technology 8: 13-15.

[36] Zhao, R. Y., Liu, D. W. (2007): Relationship between the occurrence of Dendrolimus kikuchii and weather factors. - Forest Pest and Disease 5: 26-28.

[37] Zhao, R. Y., Xu, Z. W., Luo, S. G., Yang, S. L. (2003): Techniques of forecasting and predicating Dendrolimus houi. - Journal of Zhejiang Forestry College 1: 49-53.

[38] Zhou, Y. J., Lin, H. Y., Hua, Y., Han, X. H., Wei, Z. Y., Zhang, F. P. (2019): Occurrence regularity and biological characteristics of Dendrolimus houi in Fujian Province. Subtropical Agriculture Research 15(1): 20-26.

[39] Zhu, G. P., Liu, G. Q., Bu, W. J., Gao, Y. B. (2013): Ecological niche modeling and its applications in biodiversity conservation. - Biodiversity Science 21(1): 90-98. 